Brit. J. industr. Med., 1961, 18, 33.

\title{
THE CAUSES OF DEATH IN IRON AND STEEL WORKERS (NON-FOUNDRY)
}

\author{
BY \\ A. I. G. MCLAUGHLIN and H. E. HARDING \\ From the Department for Research in Industrial Medicine (Medical Research Council), London Hospital, \\ and the Pathology Department, Salisbury General Hospital
}

(RECEIVED FOR PUBLICATION JULY 5, 1960)

\begin{abstract}
Few studies have been made of the pathology associated with the iron and steel trades other than foundries. We review here the clinical, occupational, and pathological (post-mortem) findings in 10 grinders and 16 other non-foundry workers in iron and steel. Grinding is evidently a less dangerous trade than it was 100 or even 50 years ago, but silicosis and/or mixed dust fibrosis is still found amongst them. The risk of the onset of pneumoconiosis in other workers in these trades is small, but not absent.
\end{abstract}

For 15 years or so we have been collecting pathological material to study the causes of death in iron and steel foundry workers, and our observations have been published in two articles (Harding, Gloyne, and McLaughlin, 1950; McLaughlin and Harding, 1956). During the investigation 31 iron and steel workers who had not worked in foundries were included. Of these 10 came from the grinding trades (cutlery, edge tools, and files); five were welders or oxyacetylene cutters (described elsewhere, Harding, McLaughlin, and Doig (1958) ); three were forgehands and two were steel sawyers. The remaining 11 cases were single examples of different occupational categories, such as steel roller, steel chipper, sinter plant worker, metal planer, iron miller, iron tube worker, boilermaker, chain blacksmith, file scourer, engineer's turner, and steelworks foreman. All were cases reported to the coroner because of accident, suicide, sudden death, or because a claim for compensation was contemplated by relatives. They thus represent only a (small) proportion of deaths during the period of collection. When one considers the wealth of pathological material which must have been seen in the industrial towns there are surprisingly few published studies which have described the pathology associated with the various trades, with the exception of grinders. And even on this subject, the major work was done early in the last century.

The grinding trades, particularly in Sheffield, have attracted a good deal of attention from the medical profession; the most important early work on the subject was the comparatively little-known book by
Calvert Holland, "Diseases of the Lungs from Mechanical Causes" (1843), which dealt in more detail with the subject than C. T. Thackrah's earlier and better-known work "The Effects of the Arts, Trades and Professions" (1831). Holland practised in Sheffield, the home of the grinding industry, whereas Thackrah worked in Leeds and did not have as much first-hand experience of the industry as Holland did. It was the advent of the steam engine and the subsequent Industrial Revolution which brought about and emphasized the dangers of grinding. Calvert Holland points out that "previous to the employment of steam as a propulsive power, all grinding wheels were situated on rivers in the neighbourhood, at a distance varying from two to five miles, and in the midst of scenery exquisitely picturesque and beautiful. The consequence was that, whether the grinder were resident in the country or the town, he had the advantage of an abundance of fresh air and daily exercise. Besides these circumstances, which are well calculated to preserve the animal system in health, he had frequent holidays, from the supply of water being either too great or too small, so that his application was less continuous than under the new system which has none of these interruptions. At the time dry grinding was almost unknown. The introduction of it has been owing to the gradual diminution in the scale of wages. The one process is much more expeditious than the other, and is now (1843) extensively employed". By clinical and autopsy studies Holland clearly distinguished silicosis from tuberculosis and, like Peacock and Greenhow some 
20 years later, did so without the help of bacteriology or radiographs. He makes a vigorous attack on Laennec, with whom he had worked in Paris, for denying that the "concrétions osseuses crétacées du poumon" found in workmen in certain dusty trades could possibly be caused by dust.

Arnold Knight in 1844 stated that "in Sheffield there are some 2,500 grinders at work. About 150 are fork grinders; these die between the 28th and 32nd year. The razor grinders, who grind wet, die between the 45th and 50th year". Earlier (1819) he had suggested that criminals might be employed for the process of dry grinding.

Artificial abrasive wheels were introduced about 1910 for hand grinding of razors, and in the next two years the use of these wheels extended to handgrinding of pen and pocket blades (Law, 1929). Artificial wheels are now used for the grinding of other articles, with the exception of saw grinding in which the sandstone wheel is still used. There are no regulations against the use of sandstone wheels and it has been stated that they are being reintroduced for the grinding of articles other than saws. In machine file grinding artificial abrasive segmented wheels have almost entirely replaced sandstones during the last 20 years.

\section{Grinders}

In Table 1 details are given of the pathological lesions and the causes of death in 10 grinders, of whom one worked in the cutlery trade, five in the edge tool, and four in the machine file grinding trade. In all 10 cases, silicosis and/or mixed dust fibrosis were found, mainly in a fairly advanced stage, though the immediate cause of death varied from case to case. Three had massive silicosis; four others had a mixture of moderate silicosis and mixed dust fibrosis; one had moderate silicosis, another moderate mixed dust fibrosis and the tenth case had slight mixed fibrosis and extensive tuberculosis which was the actual cause of death. In only one other case was tuberculosis the cause of death though it was present in two others. In one of these tuberculosis was found in the hilar glands but not in the lungs. Fibrosis due to dust was a definite factor in the cause of death in three cases; in three others it was a doubtful factor because though silicosis and/or mixed dust fibrosis was advanced, the actual cause of death was coronary thrombosis in two and carcinoma of the bronchus in one; and in four others dust fibrosis was not a factor, the causes of death being tuberculosis, coronary thrombosis, operation for carcinoma of the bladder, and carcinoma of the bronchus. Coronary thrombosis was the immediate cause of death in three cases.

Chemical analyses of the lungs were made in only three of these 10 cases. The ash averaged $4.52 \%$; total silica $0.36 \%$; free silica $0.26 \%$; iron $\left(\mathrm{as}_{2} \mathrm{Fe}_{2} \mathrm{O}_{3}\right)$ $1.80 \%$ of the weight of the dried lung.

It is a point of interest that generally silicosis was found when the grinders had used sandstones mainly, but when during the course of their working lives they changed to artificial abrasive wheels mixed dust fibrosis was the predominant lesion.

The average age at death of these 10 cases was 58.9 years. In the early 1800 's the average age was under 40 years.

Case 1.-C.H., aged 62 at death. He began work in 1903 and worked as an office boy for two years; for nine years he worked as an edge tool grinder (using sandstone wheels) after which he served in the army for four years between 1914 and 1919 . On return to civilian life he again worked as an edge tool grinder until 1942 (23 years), again using sandstones. In 1936 he was away from work for six months on account of spontaneous pneumothorax. Tuberculosis was not found. Radiographic examination showed "heavy conglomerate silicosis in both lungs". In 1942 he gave up grinding because it was too heavy for him and he worked as a labourer in a steel works until 1950. He died in April 1951, and autopsy showed the presence of massive silicosis and cor pulmonale.

On naked eye examination the lungs showed massive subapical fibrosis with central necrosis in both lungs. Elsewhere there were scattered, partially calcified, discrete nodules, about $\mathbf{0 . 2 5}$ in. in diameter, decreasing in numbers towards the bases. Bullous marginal emphysema was present. The hilar nodes were large, very hard, and partially calcified.

On microscopic examination conglomerate nodular

TABLE 1

GRINDERS

\begin{tabular}{|c|c|c|c|c|c|c|c|}
\hline \multirow{2}{*}{ Trade Group } & \multirow{2}{*}{ No. } & \multicolumn{3}{|c|}{$\begin{array}{l}\text { Pneumoconiosis as } \\
\text { Cause of Death }\end{array}$} & \multirow{2}{*}{$\begin{array}{l}\text { Pulmonary } \\
\text { Tuberculosis }\end{array}$} & \multirow{2}{*}{$\begin{array}{c}\text { Carcinoma } \\
\text { Bronchus }\end{array}$} & \multirow{2}{*}{$\begin{array}{l}\text { Coronary } \\
\text { Thrombosis }\end{array}$} \\
\hline & & Factor & Doubtful & Not & & & \\
\hline $\begin{array}{l}\text { Edge tool } \\
\text { Machine file } \\
\text { Cutlery }\end{array}$ & $\begin{array}{l}5 \\
4 \\
1\end{array}$ & $\begin{array}{l}2 \\
1 \\
0\end{array}$ & $\begin{array}{l}2 \\
1 \\
0\end{array}$ & $\begin{array}{l}1 \\
2 \\
1\end{array}$ & $\begin{array}{l}0 \\
3 \\
1\end{array}$ & $\begin{array}{l}1 \\
1 \\
0\end{array}$ & $\begin{array}{l}1 \\
2 \\
0\end{array}$ \\
\hline Total & 10 & 3 & 3 & 4 & 4 & 2 & 3 \\
\hline
\end{tabular}




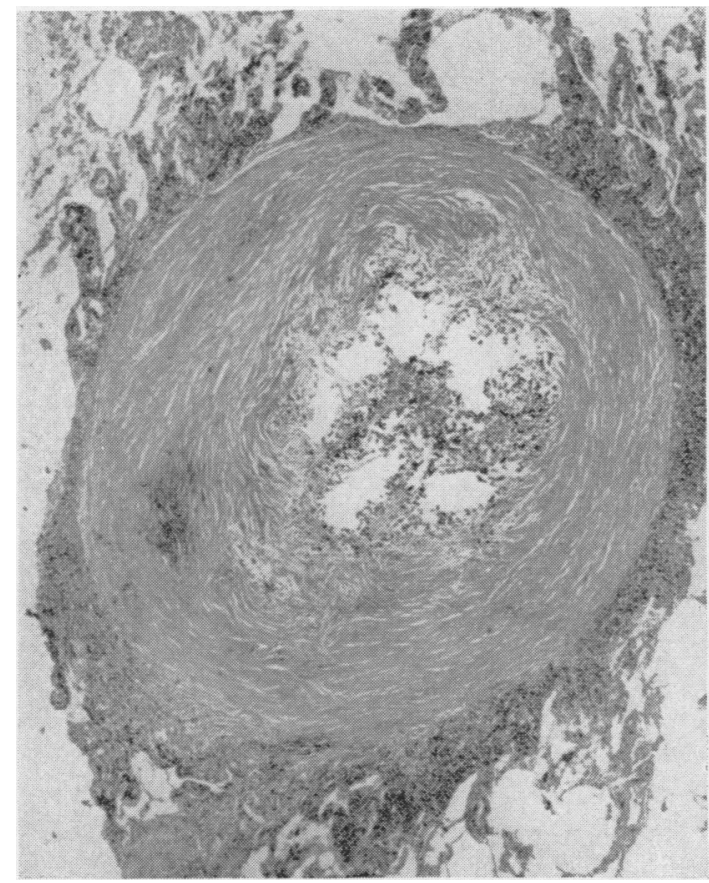

FIG. 1.-Silicotic nodule with ischaemic necrosis in its centre (Case 1). (Haematoxylin and Eosin $\times 6$.)

silicosis (Fig. 1) was present, with slight calcification and breaking down in places. There were also areas of mixed dust fibrosis (Fig. 2). No tuberculosis was seen.

Chemical Analysis.-Ash 3.76\%; total silica 0.59\%; free silica $0 \cdot 37 \%$; iron (as $\mathrm{Fe}_{2} \mathrm{O}_{3}$ ) $1 \cdot 37 \%$ of dried weight of the lung.

COMMENT.-Massive partially calcified silicosis with some mixed dust fibrosis in an edge tool grinder who had been exposed 32 years to the dust of sandstone wheels.

Case 2.-G.S., aged 66 at death. He began work in 1900 at 14 years of age and worked until 1914 as an edge tool grinder, using sandstone wheels. From 1914-19 he was on army service. After the war he worked at the same factory as a sandstone edge tool grinder until 1934 when he was obliged to stop work on account of lung trouble coupled with rheumatoid arthritis. His general condition gradually deteriorated and in 1940 he was admitted to hospital where he remained until his death in February, 1951. He had thus been exposed to the dust of sandstone grinding wheels for 29 years and was unable to work after 48 years of age, though he did not die until 17 years later.

On naked eye examination, there were pleural adhesions over the whole of both lungs. Massive greyblack very hard fibrosis was present at both apices extending down for some 2 in., where it became nodular. The mass at the right apex showed some central necrosis, but there was no evident tuberculosis. Black nodules

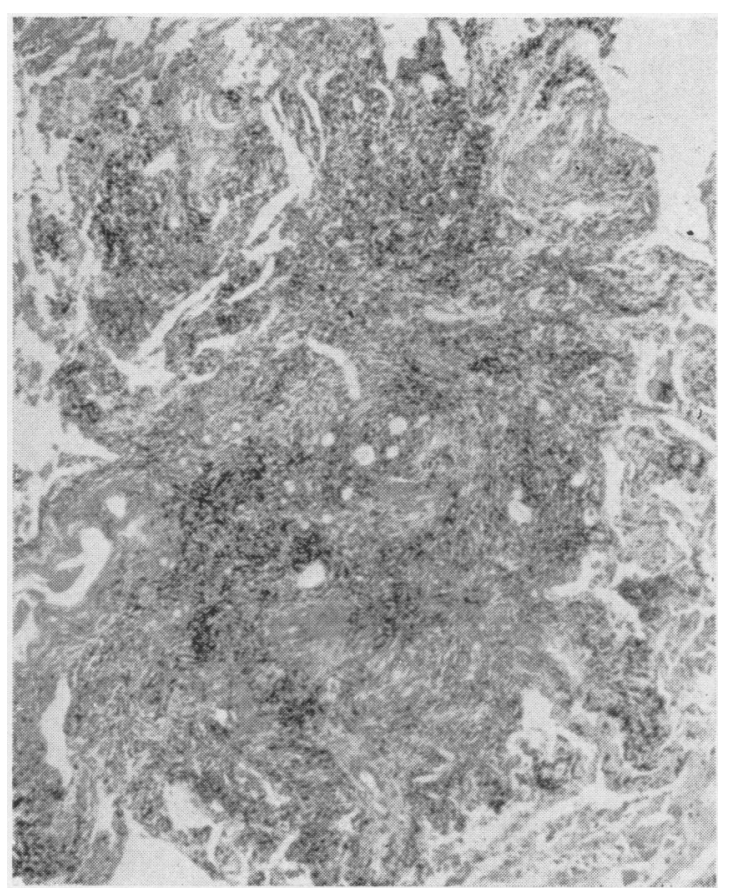

FIG. 2.-Mixed dust fibrosis (Case 1). (Haematoxylin and Eosin $\times 6$.)

with grey markings up to 0.25 in. in diameter were scattered throughout both lungs in numbers decreasing towards the bases.

On microscopic examination conglomerate and discrete silicosis was seen. Necrosis of the massive fibrosis was present, as well as calcification in the lungs and the hilar lymph nodes. In addition there was bronchitis and oedema. Neither tuberculosis nor Caplan's nodules were seen.

Chemical Analysis.-Ash 8.56\%; total silica 0.24\%; free silica $0 \cdot 16 \%$ and iron (as $\left.\mathrm{Fe}_{2} \mathrm{O}_{3}\right) 0 \cdot 19 \%$ of the dried weight of the lung.

COMMENT.-An edge tool grinder using sandstone wheels for 29 years died from massive silicosis without tuberculosis at the age of 66 , though he had been totally disabled since 48 years of age.

Of the six grinders (five edge tool and one cutlery) four had extensive or moderate silicosis or mixed dust fibrosis, one had slight silicosis and mixed dust fibrosis, and one had only very slight mixed dust fibrosis. This last man died of tuberculosis. Tuberculous lesions were found in the hilar lymph nodes in another case, but not in the lungs. The other four cases showed no evidence of tuberculosis. In two cases fibrosis due to dust was a definite factor in the deaths, in two it was doubtfully a factor (one coronary thrombosis, one carcinoma of bronchus) 
and in two it was not a factor (one operation for partial cystectomy, one tuberculosis). Chemical analyses were made on only three. Lung ash averaged $4.52 \%$; total silica $0.36 \%$; free silica $0.26 \%$, iron $\left(\right.$ as $\left.\mathrm{Fe}_{2} \mathrm{O}_{3}\right) 1 \cdot 80 \%$.

\section{Machine File Grinders}

These workers grind files in machines, fitted with sandstone wheels, running in tanks of water. In the last 20 years or so abrasive wheels have been used. They do not have to bend over the grinding wheels as closely as do the grinders of edge tools. The four cases in the series had been employed on the same job all their working lives. Two of them died at 64 years of age, one at 61 , and the fourth at 41 years of age. All showed silicotic nodules and mixed dust fibrosis, in moderate degree. Three of them had pulmonary tuberculosis, inactive in one. Two died from coronary thrombosis; one had bronchiectasis; two had generalized fine emphysema; two had focal emphysema of slight degree. On chemical analysis the average lung ash was 3.01\% (ranging from 1.95 to 3.80$)$; total silica $0.34 \%(0.28-0.55)$; free silica $0.26 \%(0.13-0.41)$; iron (as $\left.\mathrm{Fe}_{2} \mathrm{O}_{3}\right) \quad 0.44 \%(0.39$ 0.61). Pneumoconiosis was considered to be a factor in the death of one, a doubtful factor in one, and not a factor in two, who died from coronary thrombosis.

Case 3.-E.B. died at age of 41 . All his working life was spent at one factory as a machine file grinder. He became ill with symptoms of cough, dyspnoea, and expectoration at 39 years of age, and died two years later from silicosis and tuberculosis complicated by bronchiectasis.

On naked eye examination the left lung showed moderate generalized emphysema, with scattered pigmented areas, most of them soft, but a few hard nodules up to 2 in. in diameter. The right lung was small with a dense pleura, tuberculosis in right upper lobe, and in addition there were present hard conglomerate nodules. At the right base there was an area of bronchiectasis.

Microscopical examination (Fig. 3) showed silicotic and tuberculous nodules, with some areas of mixed dust fibrosis. Generalized fine emphysema (and ? focal) was also present.

Chemical Analysis.-Right lung: ash 3.80\%; total silica $0.55 \%$; free silica $0.41 \% ; \mathrm{Fe}_{2} \mathrm{O}_{3} 0.39 \%$ and left lung: ash $2.59 \%$; total silica $0.42 \%$; free silica $0.25 \%$; $\mathrm{Fe}_{2} \mathrm{O}_{3} 0.51 \%$ of the dried weight of the lung.

Comment.-A machine file grinder who died at 41 years of age after 24 years exposure. Death was due to pneumoconiosis with cor pulmonale, with slight tuberculosis and bronchiectasis. Chemical analysis showed that the right lung had retained more dust with the exception of iron than the left.
Case 4.-H.H., 61 years of age at death, was a machine file grinder all his working life (about 47 years) at one firm. He died suddenly at home in January, 1950 and at autopsy death was found to be due to coronary thrombosis.

On naked eye examination of the lungs, the pleural lymphatic markings were seen to be exaggerated. There were hard black nodules throughout the lungs, but more in the upper lobes, mainly small (1-2 mm.); a few nodules were larger. There was also generalized fine emphysema and pulmonary congestion. No tuberculosis was present. The hilar nodes were large and black with grey hard areas.

Microscopical examination showed discrete silicotic nodules (Fig. 4) with areas of mixed dust fibrosis (Fig. 5), associated with focal emphysema. In addition there was congestion and oedema of the lungs. In the hilar lymph nodes were aggregates of silicotic nodules.

Chemical Analysis.-Ash 1.95\%, total silica 0.18\%, free silica $0.13 \%$, and iron $\left(\right.$ as $\left.\mathrm{Fe}_{2} \mathrm{O}_{3}\right) 0.46 \%$, of the dried weight of the lungs.

Comment.-A machine file grinder who died at 61 years of age from coronary thrombosis. Silicosis and mixed dust fibrosis were present in the lungs. Dust was not a factor in the immediate cause of death.

Case 5.- J.H.C. died at the age of 64 . He was a machine file grinder who had used sandstone all his working life (approximately 50 years) at one firm. Had suffered from a cough and dyspnoea for some years before his death, and three months before had been away from work for five weeks on account of "pleurisy". He died suddenly at home and autopsy showed that the cause of death was coronary thrombosis. There was an old thrombus in the left coronary artery and a recent one in the right. The left ventricle was thinned and fibrotic at the apex.

Examination of the lungs showed old pleural adhesions on both sides especially over the apices. In the apical regions also there were masses of fibrous tissue enclosing dry partially calcified caseous material. Throughout the lungs, were small, very hard calcified nodules. In addition there was focal emphysema.

On microscopical examination both mixed dust fibrosis and silicotic nodules were seen. The apical masses were composed of silico-tuberculosis. Fig. 6 shows an area where there is a conjunction of silicotic nodules and mixed dust fibrosis.

COMment.-A machine file grinder of 50 years exposure who, though he died from coronary thrombosis, had well-marked silico-tuberculosis and mixed dust fibrosis.

\section{Engineering Machine Shop Workers}

Post-mortem examinations were conducted on seven men (two steel sawyers, a metal planer, an iron miller, an engineer's turner, a magnet inspector, and a boilermaker) whose ages ranged from 48 to 69 years with an average of $59 \cdot 3$, and most of whom had been employed on the same job for $\mathbf{3 0}$ or more years. 


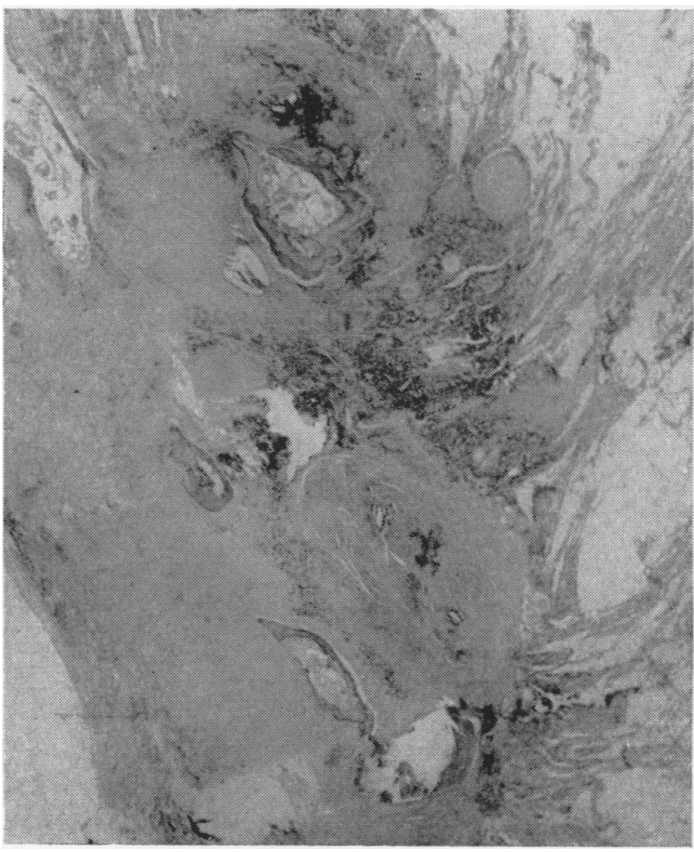

FIG. 3

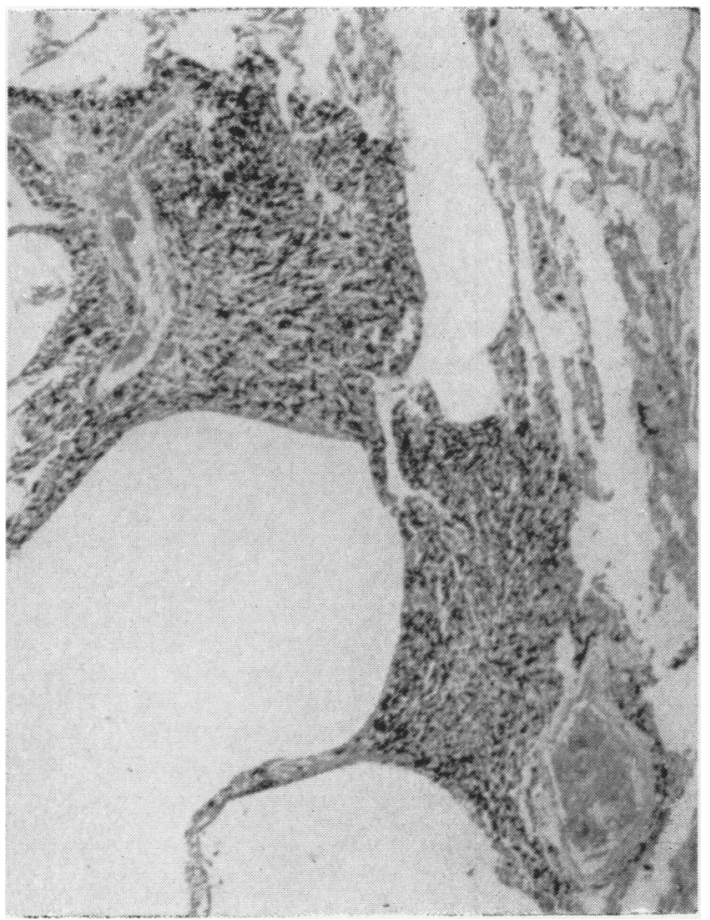

Fig. 5

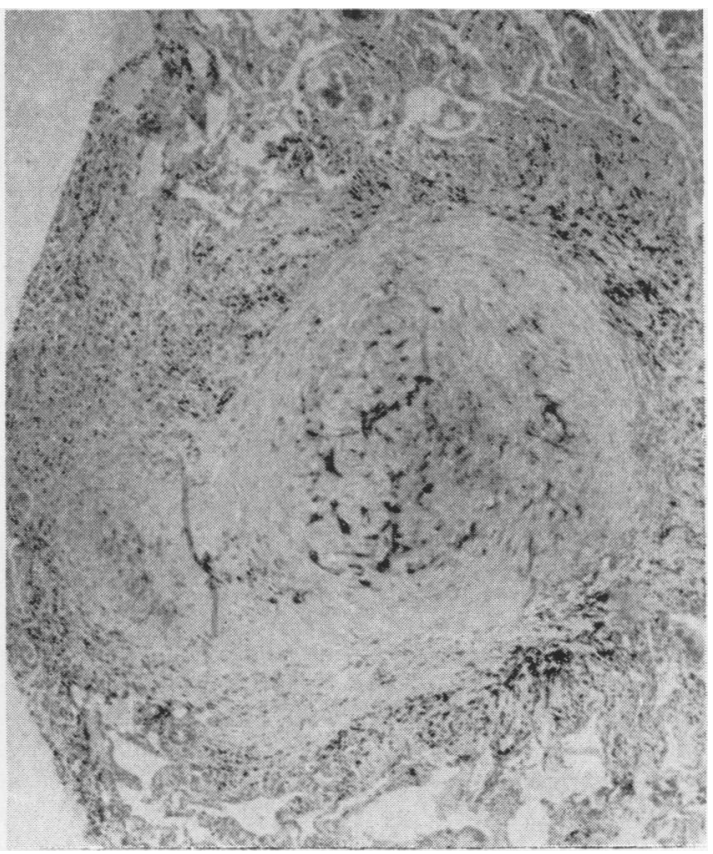

Fig. 4

FIG. 3.-Conglomerate silicotic nodules. Bone formation in hyaline fibrous tissue (Case 3). (Haematoxylin and Eosin $\times 6$.)

Fig. 4.-Silicotic nodule(s) (Case 4). (Haematoxylin and Eosin $\times 6$.) Fig. 5.-Mixed dust fibrosis: focal emphysema (Case 4). (Haematoxylin and Eosin. $\times 8$.)

Fig. 6.-Conjunction of silicotic nodule and mixed dust fibrosis (Case 5). (Haematoxylin and Eosin $\times 6$.)

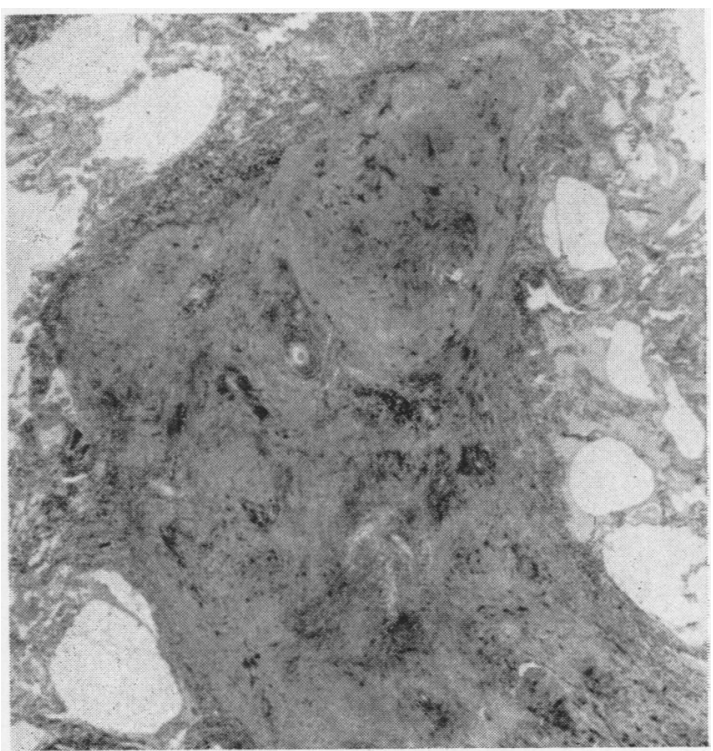

Fig. 6 
TABLE 2

OTHER NON-FOUNDRY WORKERS

\begin{tabular}{|c|c|c|c|c|c|c|c|}
\hline \multirow{2}{*}{ Trade Group } & \multirow{2}{*}{ No. } & \multicolumn{3}{|c|}{$\begin{array}{l}\text { Pneumoconiosis as } \\
\text { Cause of Death }\end{array}$} & \multirow{2}{*}{$\begin{array}{l}\text { Pulmonary } \\
\text { Tuberculosis }\end{array}$} & \multirow{2}{*}{$\begin{array}{c}\text { Carcinoma } \\
\text { Bronchus }\end{array}$} & \multirow{2}{*}{$\begin{array}{l}\text { Coronary } \\
\text { Thrombosis }\end{array}$} \\
\hline & & Factor & Doubtful & Not & & & \\
\hline $\begin{array}{l}\text { Engineering machine shop } \\
\text { Forgehands } \\
\text { Steel roller } \\
\text { Sinter plant worker } \\
\text { File scourer } \\
\text { Steel chipper } \\
\text { Fireman }\end{array}$ & $\begin{array}{l}7 \\
4 \\
1 \\
1 \\
1 \\
1 \\
1\end{array}$ & $\begin{array}{l}0 \\
1 \\
0 \\
0 \\
0 \\
0 \\
0\end{array}$ & $\begin{array}{l}1 \\
0 \\
0 \\
0 \\
0 \\
0 \\
0\end{array}$ & $\begin{array}{l}6 \\
3 \\
1 \\
1 \\
1 \\
1 \\
1\end{array}$ & $\begin{array}{l}1 \\
1 \\
0 \\
0 \\
1 \\
0 \\
0\end{array}$ & $\begin{array}{l}\mathbf{0} \\
0 \\
0 \\
0 \\
0 \\
0 \\
0\end{array}$ & $\begin{array}{l}0 \\
1 \\
1 \\
0 \\
0 \\
1 \\
1\end{array}$ \\
\hline Total & 16 & 1 & 1 & 14 & 3 & 0 & 4 \\
\hline
\end{tabular}

Four of them showed slight or very slight mixed dust fibrosis, one a doubtful fibrosis, and two no fibrosis. In six, pneumoconiosis was not a factor in death from hypertension, uraemia from chronic nephritis, cor pulmonale due to acute or chronic bronchitis, acute bronchopneumonia, accident, and suicide. In one case, the boilermaker, it was a doubtful factor in death that resulted from an extreme degree of atrophic emphysema. Chemical analysis of five of the lungs gave as an average of the dried weight of the lung, ash $2.37 \%$, total silica $0.25 \%$, free silica $0.14 \%$, and iron (as $\mathrm{Fe}_{2} \mathrm{O}_{3}$ ) $0.49 \%$

This small series suggests that pneumoconiosis is not an important risk in this part of the industry.

Case 6.-D.W.B. worked as a boiler maker after leaving school: he never cleaned boilers. For his last 12 years at work he was a foreman, inspecting boilers. He gave up work several months before he died at the age of 48 .

The lungs were received by us after fixation and some cutting. They showed extreme emphysema of atrophic type with bullae at the apices and anterior margins. The cut surfaces were black but without definite fibrosis. The hilar lymph nodes were moderately enlarged, black but fairly soft.

Microscopically there was slight mixed dust fibrosis: much of the dust was in collections of phagocytes in some alveoli. Emphysema was a notable feature, generalized and not evidently focal. The hilar lymph nodes contained only a little dust and showed no fibrosis.

Chemical ANAlysis.-Ash 2.87, total silica $0 \cdot 31$, free silica 0.15 , and iron, expressed as $\mathrm{Fe}_{2} \mathrm{O}_{3}, 0.93$, expressed as percentages of dried weight of the lung.

CoMment.-Minimal pneumoconiosis and marked general emphysema in a man of 48 years of age who had had 34 years' experience of boilermaking. It is doubtful whether pneumoconiosis was a factor in his death.

\section{Forgehands}

Three forgehands and a chain blacksmith aged 48 , 43,54 , and 67 years respectively were encountered (Table 2). One had silico-tuberculosis, and pneumo- coniosis was considered to have been a factor in his death. Slight mixed dust fibrosis was present in the lungs of the other three cases, but was not considered a factor in their deaths, from accident, coronary thrombosis, and acute bronchopneumonia following chronic bronchitis. The average chemical findings in the three who did not have tuberculosis, expressed as a percentage of weight of dried lung, were ash $2 \cdot 87$, total silica $0 \cdot 28$, free silica $0 \cdot 19$, and iron (as $\mathrm{Fe}_{2} \mathrm{O}_{3}$ ) 0.32.

Case 7.-A.H.B. entered the forging shop soon after leaving school and remained there the rest of his life, rising in responsibility to foreman forgehand. $\mathrm{He}$ worked on the same hammer for his last 10 years. He died at the age of 43 years as the result of an accident at work, when the handle of a tongs was driven into his pelvis tearing the right iliac artery.

To the naked eye the lungs showed non-palpable black patches and spots on the pleurae, and small non-palpable black areas scattered throughout the lungs. Microscopically there was very slight mixed dust fibrosis in the lungs (Fig. 7), and pigmentation without fibrosis in hilar lymph nodes.

Chemical Analysis. Ash $2 \cdot 55$, total silica 0.15, free silica $0 \cdot 14$, and iron (as $\left.\mathrm{Fe}_{2} \mathrm{O}_{3}\right) \mathbf{0 \cdot 3 9}$, all as percentages of the weight of dried lung.

Comment.-Very slight mixed dust fibrosis was not a factor in the death by accident of a man employed as a forgehand for 29 years.

\section{Miscellaneous Workmen}

Case 8.-A sandblaster and scourer of files*, who was 54 when he died, had done this job all his working life for one firm. He was ill with chest trouble four years before he died and did not return to work. He was examined by the Pneumoconiosis Medical Panel who refused a certificate. His lungs showed cavitation and pigmented fibrosis at both apices, involving much of the

\footnotetext{
* The use of sand in blasting was prohibited by the Blasting of Castings (and other Articles) Regulations, 1949, but an exemption has been granted for the sandblasting of files. The process is almost entirely enclosed; a jet of steam is applied at the same time as the sand, and the enclosure is under exhaust ventilation. There is little or no risk of the inhalation of dust.
} 
upper lobes. Patches of caseous pneumonia were seen in the lower lobes. The remainder of the lower lobes showed only slight focal pigmentation and no sign of fibrosis. Microscopically there was tuberculosis of varying age: there was a fair amount of pigment in the more fibrous areas, but all the fibrosis seemed to be of tuberculous origin and it was doubtful whether there was any true pneumoconiosis.

Chemical Analysis.-Ash $1 \cdot 68$, total silica $0 \cdot 14$, free silica 0.07 and iron $\left(\right.$ as $\left.\mathrm{Fe}_{2} \mathrm{O}_{3}\right) 0 \cdot 14$, all as percentages of weight of dried lung.

Case 9.-A steel chipper*, aged 68 years, worked for one firm for 22 years: his firm say that his occupation would not have exposed him to dust. He never complained of ill health. He collapsed and died in the street, and after an autopsy his death was recorded as due to coronary thrombosis. His lungs showed marked generalized emphysema with bullae: they were much pigmented but the aggregates were only doubtfully palpable. Microscopically there were small aggregates of very dense pigment with very little fibrosis. Incinerated sections showed that much of the pigment was iron: incinerated and acid-treated sections showed hardly any doubly refractile material.

Chemical Analysis.-Ash 3.72, total silica $0 \cdot 23$, free silica $0 \cdot 10$, iron (as $\mathrm{Fe}_{2} \mathrm{O}_{3}$ ) 2.40, as percentages of weight of dried lung.

Case 10.-A sinter plant worker, aged 64 years, was a collier between the ages of 14 and 32 . From then he was employed continuously in a sinter plant, where he collapsed and died suddenly. His death was stated to be due to "chronic aortic endocarditis". The lungs showed tiny black areas of focal emphysema present mainly in the upper lobes, but no nodules were palpable with certainty. Microscopically there was slight mixed dust fibrosis and focal emphysema: whorled fibrous nodules were present in the hilar nodes.

Chemical Analysis.-Ash 1.33, total silica 0.13, free silica 0.05 , iron (as $\mathrm{Fe}_{2} \mathrm{O}_{3}$ ) 0.53 , expressed as percentages of weight of dried lung.

Case 11.-A steel roller died of coronary thrombosis. Only a large section of his lung was available for study. This showed slight marginal emphysema. Using a hand lens it was possible to see tiny areas of mixed dust fibrosis not apparent to the naked eye.

Case 12.-A steel works fireman died at 66 years of age. He had been employed as a tram driver before working for 10 years at cold sawing of steel bars. After this he became a fireman for 20 years. Seven years before he died he had an haemoptysis the cause of which was found to be mitral stenosis. Post-mortem examination showed "mitral stenosis, coronary atherosclerosis, and fibrosis of the right ventricle. He also had a gastric ulcer".

*The term "chipper" is used in the U.S.A. as a synonym for the terms "fettler" and "dresser" employed in this country. This workman was not fettling steel castings.

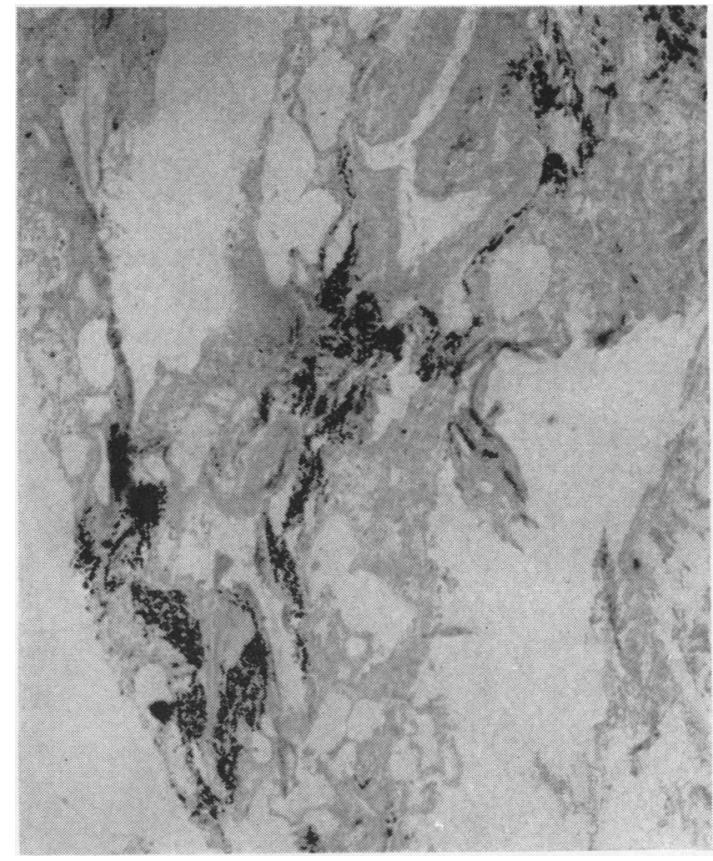

FIG. 7.-Slight mixed dust fibrosis: focal emphysema (Case 7). (Haematoxylin and Eosin $\times 6$.)

A large section of the lung showed emphysema but no fibrotic nodules. Microscopically the lungs showed no fibrosis; some pigment was seen in intra-alveolar phagocytes.

Chemical Analysis.-Ash 2.91, total silica 0.04, free silica 0.05 , and iron $\left(\right.$ as $\left.\mathrm{Fe}_{2} \mathrm{O}_{3}\right) \mathbf{0 . 8 7}$, as percentages of the dried weight of the lung.

These five workmen showed only slight or no pneumoconiosis, which was not a factor in the death of any of them. Two died of coronary thrombosis, one of chronic aortic endocarditis, one of mitral stenosis, and one of pulmonary tuberculosis.

\section{Discussion}

Grinding is evidently a less dangerous trade than it was 50 or 100 years ago, and grinders live longer. This improvement in the health of grinders results from a combination of many factors, some general to the population and some affecting the particular employment. Among the latter are the replacement of sandstone by artificial grindstones in many works, provision of exhaust ventilation, and a general raising of the standard of housekeeping in works.

Nevertheless silicosis and/or mixed dust fibrosis still affects grinders as shown in the cases listed above. Classical whorled silicotic nodules are found in men who have used sandstone grinding wheels, 
while mixed dust fibrosis is the lesion found in those using artificial stones. More remains to be done to improve the working conditions of grinders.

The position is much better in respect of other non-foundry workers in the iron and steel industries. In only one of the 16 cases reported here was pneumoconiosis considered to have been a major factor in the death of a workman, and he had pulmonary tuberculosis. The working conditions of the men in this group vary greatly; many of them have a quite insignificant risk of pneumoconiosis, but some of them have a risk that is of a lesser degree than that of foundry workers.

The photomicrographs were prepared by Mr. R. Conroy.

\section{REFERENCES}

Greenhow, E. H. (1860). In 3rd Report of Medical Officer of Privy Council. H.M.S.O., London

1865). Rep. M.O. Local Govt. Bd., H.M.S.O., London.

1865). Trans. path. Soc. (Lond.), 16, 59.

(1866). Ibid., 17, 36.

(1866). Ibid., 17, 24.

Harding, H. E., Gloyne, S. R., and McLaughlin, A. I. G. (1950) In McLaughlin, Industrial Lung Diseases of Iron and Steel Foundry Workers, H.M.S.O., London.

- McLaughlin A. I. G., and Doig A. T. (1958). Lancet, ii, 394.

Holland, C. (1843). Diseases of the Lungs from Mechanical Causes. Churchill London.

Knight, A. (1819 and 1844), Quoted from Hunter, D. Diseases of Occupations, 2nd ed., p. 124 and 849, University Press, London.

Law, J. (1929). Ann. Rep. Chief Inspector of Factories for 1928.

McLaughlin, A. I. G., and Harding, H. E. (1956). A.M.A. Arch. industr. Hlth, 14, 1350.

Peacock, T. B. (1860). Med. chir. Trans., 26, 214.

(1861). Trans. path. Soc. Lond., 12, 36.

(1865). lbid. 16,57.

Thackrah, C. T. (1831). The Effects of the Arts, Trades and Professions. Longmans, London. 